\title{
Evaluation of NSP and MPA Methods to Optimize Special Truss Moment Frames (STMF) Using Island Genetic Algorithm
}

\author{
Mohaddese Sadeghpour $^{{ }^{*}}$, Vahid Reza Kalatjari ${ }^{1}$, Hossein Pahlavan ${ }^{1}$ \\ ${ }^{1}$ Department of Civil Engineering, Faculty of Civil Engineering, Shahrood University of Technology, Shahrood 36199-95161, Iran \\ * Corresponding author, e-mail: m.sadeghpour489@shahroodut.ac.ir
}

Received: 24 August 2021, Accepted: 18 October 2021, Published online: 26 October 2021

\begin{abstract}
The purpose of the present study is to evaluate the Pushover (NSP) and Modal Pushover (MPA) analysis methods in optimizing Special Truss Moment Frames (STMF) using island genetic algorithm. For this purpose, the optimization program is written and developed in Matlab software, and OpenSees software is used for structural analysis. The design variables of truss arrangement, cross section of members, truss height values and length of special zone of truss moment frame are considered. The constraints of the optimization problem are based on the rules and restrictions of AISC341-16. Case studies were performed on five frames of 3, 6, 9, 12 and 15 stories with a story height of 3 meters and span length of 18 meters with the aim of minimizing weight and maximizing the response modification factor. The results of these analyses are compared with nonlinear dynamic time history analyses as the most accurate method available, which could be used to finally identify and introduce the most efficient method in these structures. The MPA method was able to show better performance than the NSP method in estimating the maximum response of the structure. Despite the excellent performance of this method, Evaluation of numerical results of this study indicates the non-economic nature of MPA method for low-rise structures, and the acceptable efficiency of this method for medium-height to high-rise structures.
\end{abstract}

\section{Keywords}

Island Genetic Algorithm, Response Modification Factor, Special Truss Moment Frame, Modal Pushover Analysis, Nonlinear Static Pushover Analysis

\section{Introduction}

Due to the destructive effect of recent earthquakes on structures, it has been observed that some current seismic design methods are not accurate enough, hence, the need to correct them is critically felt. To determine the required strength for seismic force, instead of nonlinear analysis, the amount of applied force to the structure by the earthquake is allowed in regulations, while the structure with elastic behavior is computed and then a reduction coefficient called response modification factor is applied [1]. In seismic regulations, this coefficient depends only on the type of system and is represented by a constant number. However, various factors affect the response modification factor including earthquake record, frequency content, soil conditions, type of structural system, ductility of materials, geometric shape of the structure, as well as the regularity and irregularity of the structure [2-4]. The effect of earthquake records on ductility capacity and response modification factor of structures can be evaluated using the results of nonlinear dynamic analysis of structures. Most nonlinear dynamic methods require a large amount of computation and are often complex and time-consuming. Furthermore, analyzing and interpreting the results require special skills and expertise. For this reason, nonlinear static pushover (NSP) or increasing nonlinear static analysis methods are used to investigate the structures entering the nonlinear zone. The two essential assumptions of this method, which cause the approximation of the analysis results when the structure enters the nonlinear zone, are the constant distribution of lateral forces and the determination of the ultimate response of the structure based on the first mode. To overcome the above-mentioned limitation, various researchers have modified the traditional nonlinear static analysis method and introduced new nonlinear static methods in which incremental load analysis for a structure with a different load pattern based on different modes is operated and then the results are combined. 
The MPA method has the ability to influence higher modes in the response of the structure. Thus, the use of these modes whose participation is determinant, such as highrise structures, is of a particular importance [5-10].

Due to the limitations of urban landscapes and the application of some structures, the design conditions require that the distance between the columns be more than the normal value. Therefore, the use of appropriate and efficient structural systems, both technically and economically, is regarded as vital. In these cases, there are various options for designing the load-bearing system of the building. One of the most effective and widely used options is adopting a frame with special truss beams, which dissipate seismic energy through special ductile sections located near the middle of the truss crater [11]. Due to the listed features, the use of these systems in buildings such as hospitals and commercial and industrial buildings has been accepted in some countries.

The needs and applications of these systems have led to relatively extensive research, especially in the nineties of the twentieth century. The first article on a special truss moment frame was published in 1994 by Goel and Itani [12]. In this study, the authors aimed to develop an advanced open-web truss-moment frame. For this purpose, in addition to experimental research, they performed several numerical analyzes to investigate the seismic performance of the system. They showed that the hysterical behavior under cyclic loads is very small and weak, and this is due to the initial buckling and failure of the truss. The nonlinear dynamic analysis also showed that such systems subjected to several severe earthquake excitations with large stratified drifts and excessive nonlinear deformations of columns and the truss network members reacts very poorly Goel and Itani [11] in a joint paper examined the potential of using X-diagonal systems. Findings from this study showed that this robust system is an excellent system with suitable seismic resistance for buildings. Basha and Goel [13] investigated potential energy dissipation in the Vierendeel truss frame.

Goel et al. [14] proposed strategies for designing special truss moment frames. They examined the quality range of the design philosophy used for STMF frames. When the STMF-specific segment surrenders and enters the nonlinear phase, causing energy loss, the other members of the system remain elastic.

Parra-Montesinos et al. [15] studied the performance of robust diameter members of reinforced double-channel built-up in STMF. They showed that the current AISC condition for lateral bracing is not sufficient to guarantee large rotational capacity in reinforced channels, and based on the test results, a new equation was proposed.

The primary goal of Chao and Goel [16] was to propose a new equation for the expected shear strength in the specific segment of the STMF truss. For this purpose, they performed a series of nonlinear dynamic and static analyzes and based on the results, they found that the AISC equation mainly overestimates the expected shear strength. Based on the findings of statistical analysis, they obtained a modified expression for the design.

Chao and Goel [17] proposed a performance-based STMF plastic design method. Prior to this study, STMFs were designed based on linear analysis. The use of linear analysis in member coordination leads to uneven distribution of floor drifts and submission in specific areas at building height. In order to achieve lateral displacement of floors and more coordinated submission, the authors considered plastic design based on performance level better.

Pekan et al. [18] presented an innovative method by combining a special truss moment frame and energy dissipator to prevent damage.

Abdollahzadeh et al. [19] evaluated the seismic fragility of special truss moment frames using capacity spectrum method.

Mousavi et al. [20] investigated the effect of geometry parameters on the behavior of special truss moment frames.

Kumar and Sahoo [21] investigated the performance of special truss moment frames with several Vierendeel openings in tall structures. They showed that STMFs having the special segments of the higher aspect ratio and the multiple Vierendeel panels exhibited the desired yield mechanisms and satisfied the acceptance criteria. Also recommended that the limiting values of the panel aspect ratio and the overall height of STMFs.

These studies eventually led to the development of design codes in this field. AISC341-16 [22] code devotes a topic to the STMF truss moment-resisting frame and considers the rules and limitations of these frames. However, the factor of response modification of this frames has not been studied to date. Therefore, in this study, calculation of optimal response modification factor is presented. In this study, optimization of truss arrangement, cross section of members, truss height and length of special zone of truss moment-resisting frame have been done to obtain the best seismic performance using island genetic algorithm [23-26]. The optimization objective is to minimize frame weight and maximize the response modification 
factor. To achieve this aim, the response modification factor is obtained from NSP and MPA analyzes for the safety performance level of LS. Finally, the optimization results of NSP and MPA analyzes were evaluated and compared with time history analysis.

\section{The Special Truss Moment Frame (STMF)}

Generally, engineers have been compelled to use special bending frames with long spans because of the architectural limitations or structural specifications, which trigger the geometric characteristics of the sections of beams and columns to be too high [27]. To solve this problem, a system entitled Special Truss Moment Frame has been proposed, which reduces the sections of the members and also reduces the relative displacement of the floors with better functional conditions. Special truss can be designed in three forms: $\mathrm{x}$-diagonals, Vierendeel, and multiple Vierendeel panels (Fig. 1) [22, 28].

These frames are more economical, easily attached to the column, and lighter than frames made of plate girders. Also, the openness of these trusses allows better use of the space required by the facility. As another advantage of this system, it can be referred to the fact that an indefinite degree can be increased, by the help of deep beams and by increasing the number of webs in special parts, eventually resulting in greater overall structural difficulty [29].

\section{Nonlinear Static Analysis}

\subsection{Nonlinear Static Pushover Analysis (NSP)}

In the present method, the structure is examined under a lateral load in accordance with the load distribution pattern of the applied code, until the lateral displacement reaches its corresponding value. Estimation of seismic needs of the structures in this method is done by determining the performance point, while the performance point in

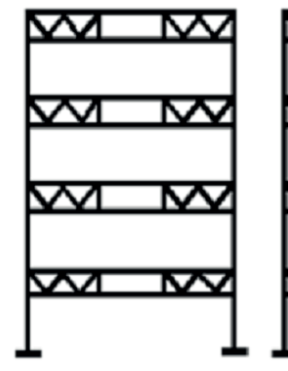

(a)

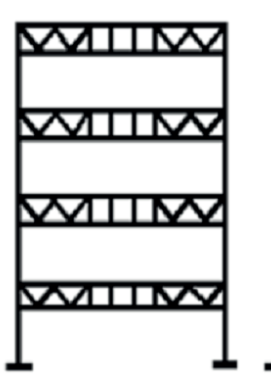

(b)

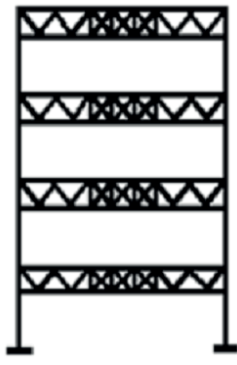

(c)
Fig. 1 Frame with special truss beam (a) Vierendeel, (b) Multiple Vierendeel Panels, and (c) X-Diagonals these methods is the displacement of the roof, at which, forces, displacements, and internal stresses are all calculated. In this analysis, both the force distribution and the target displacement are based on the assumption that the response of the structure is controlled by the first mode and the fact that the shape of the mode does not change after the yielding of the structure $[6,7]$.

\subsection{Modal Pushover Analysis (MPA)}

Chopra and Goel [5] first developed the Modal Pushover Analysis (MPA), which was based on structural dynamics theory, the conceptual simplicity and computational attractiveness as its salient features. In the Modal Nonlinear Pushover Static Analysis method, response of the structure is calculated by assistance of the concept of equivalent one degree of freedom structure by applying arbitrary earthquake accelerogram, maximum displacement of one degree of freedom structure under the effect of the accelerogram of the nonlinear dynamic response history analysis and with multiplying this term in modal participation factor, target displacement of the structure is obtained in every required mode. Then, in each mode separately, nonlinear pushover static analysis is conducted on the main structure and under the effect of lateral force based on desired mode shape until the target displacement is reached. Finally, the optimal response is determined by combining the responses obtained from the nonlinear pushover analysis of the structure in each mode $[6,10]$. The main steps of MPA can be summarized as Fig. 2.

\section{Response Modification Factor}

The response modification factor of the structure is obtained by multiplying several coefficients, each of which includes a specific feature of the structure in withstanding the forces and deformations introduced by the earthquake $[2,3] . R_{\mu}$ is the coefficient of ductility and dissipated energy due to residual behavior, $R_{s}$ is the slope due to the structural strength overload. The response modification factor of multi-degree-of-freedom systems is calculated through the following equation:

$$
R=R_{\mu} R_{s}
$$

As shown in Fig. 3, the real non-linear behavior of a structure can be modeled with a two-line relationship, based on which, the response| modification factor components can be determined. 


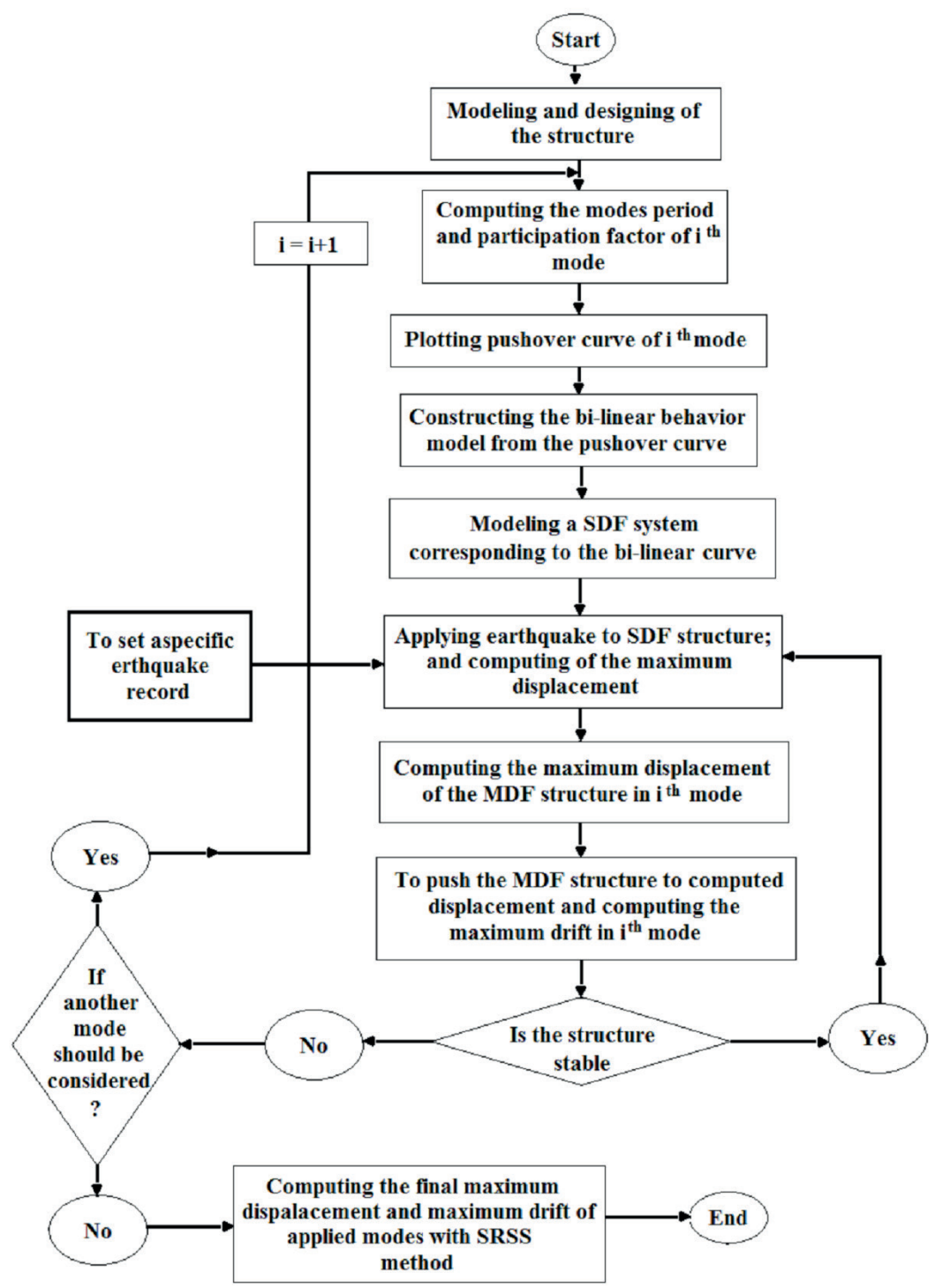

Fig. 2 MPA working flowchart

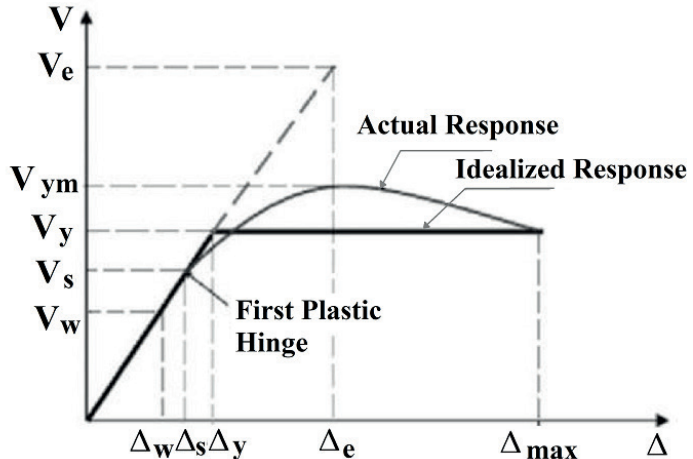

Fig. 3 General behavior of force-displacement of structures

The ductility of the structure, which shows the energy absorption and dissipation capacity in the structure, is a function of the structure behavior after its yield and according to Fig. 3 is obtained from the Eq. (2):

$$
\mu=\frac{\Delta_{\max }}{\Delta_{y}} .
$$

Due to the ductility and nonlinear response of the structure, the linear force $V_{e}$ of the structure can be reduced to the force $V_{y}$. Therefore, the force reduction factor can be defined according to the relationship Eq. (3):

$$
R_{\mu}=\frac{V_{e}}{V_{y}} .
$$

Also, the ratio of the base shear of the actual collapse mechanism in the structure $V_{y}$ to the base shear of the first yield level in the structure $V_{s}$ is called Overstrength, which is defined according to Eq. (4):

$$
R_{s}=\frac{V_{y}}{V_{s}} .
$$




\section{Theoretical fundamentals and formulation of the problem}

\subsection{Island Genetic Algorithm}

Genetic algorithm, as one of the most widely used methods of evolutionary algorithm, has been extensively used in various sciences. Genetic algorithm is regarded as an effective search method in large spaces that ultimately leads to the orientation towards finding the optimal answer. In genetic algorithms to solve a problem, the evaluation function may be conducted hundreds or thousands of times, so depending on the time required to perform the evaluation function, a genetic algorithm may take hours, days, or even months to reach an acceptable solution.

Island genetic algorithm is one of the powerful and novel methods of genetic algorithm, in which, a large population is divided into a smaller subset and the conventional genetic algorithm with different operators and parameters is applied separately to each subpopulation. In general, this algorithm includes a number of processes, each of which runs a series of genetic algorithms independently. Hence, each of these populations is referred to as an island. These islands exchange at regular intervals, which is called migration information. During the migration process, a relatively small number of chromosomes from each island are sent to another island at specified intervals based on a specific topology, these chromosomes are called the immigrant chromosomes. Much work has been done to select the best migration topology, but the hyper-cube topology seems to be the best $[30,31]$.

In the immigration process, two parameters are defined as follows:

1. Immigration interruption, which indicates the number of generations between each transfer.

2. Immigration rate indicates the percentage of members selected to transfer from each islands at the time of transfer.

The selected migration method is a loop with random destinations in which each sub-population has a random destination and these destinations are randomly identified in each migration period. The immigration operator sends the best of a sub-population to another island, which is comprised of the environment and members with different anatomy. Following the migration process, the genetic algorithm combines the immigrating populations with the rest of the population and takes the steps to achieve a better fit population [30].

Therefore, in the island method, the convergence is faster and the number of each subpopulation is smaller, since a large population becomes a number of subpopulations.
In the present re|search method, due to the immigration mechanism, the answers benefit from a certain variety during the search process. On the one hand, this search method explores the design space more thoroughly. On the other hand, in this method, all valid and efficient methods introduced by researchers can be used, due to the unique characteristics of the space of each island. In other words, each optimization problem is explored in one or several methods, then the design space is explored, and consecutively the best results are shared among other islands and new populations are provided for each island for breeding [31]. These properties reduce the impact of the parameters and also the governing relations on the operation of the genetic algorithm, thus, it dramatically increases the convergence rate of the algorithm. Fig. 4 illustrates the flowchart of the Island Genetic algorithm.

\subsection{Objective function of design}

The purpose of the objective function of the design is to minimize the weight of the structure and to maximize the response modification factor at the performance level of life safety. Truss arrangement optimization, member cross section, truss height and special zone length are considered as the design variables. This objective function can be represented as follows [32]:

Objective Function $=W+\frac{70 W}{R^{1.4}}+W K_{g} C_{g}$,

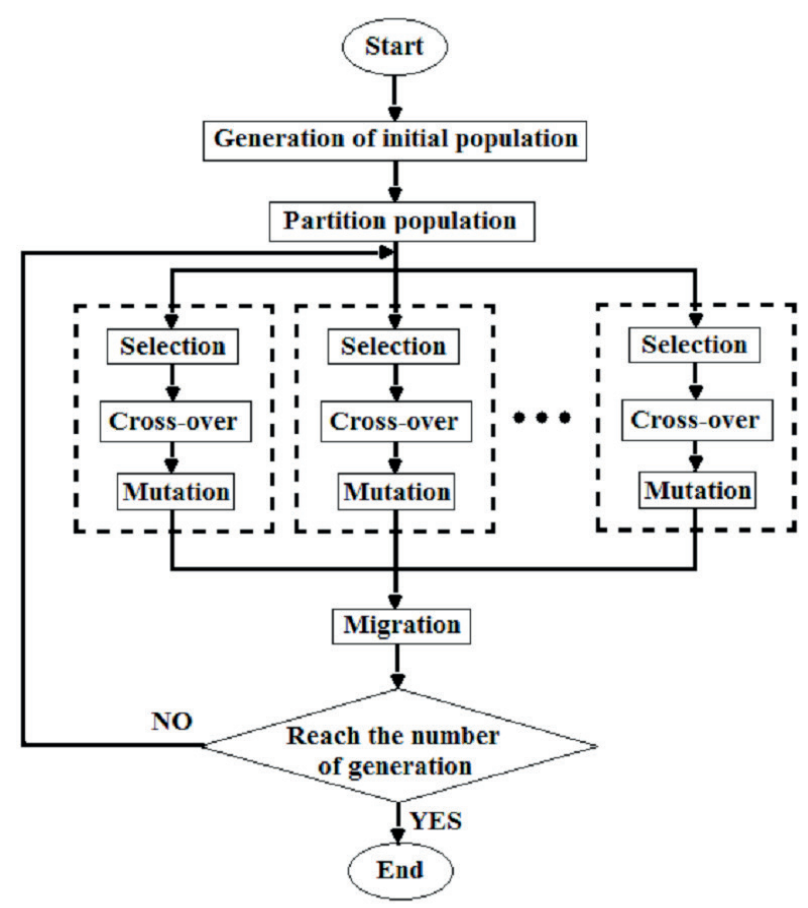

Fig. 4 The flowchart of the Island Genetic algorithm? 
where $C_{g}$ is the summation of the constraints of the problem, $K_{g}$ is the penalty coefficient (the coefficient of the penalty function equals to 10), $R$ is referred to the response modification factor of the structure which is calculated in this study using NSP and MPA analysis and $W$ is the weight of the structure which is obtained from the following relation:

$W=\sum_{i=1}^{n} \rho A L$,

whereas $\rho$ is the weight density, $n$ is the number of the member, and $A$ and $L$ indicate the cross- section and length of the member, respectively.

\subsection{Design constrains}

The applied constraints in this research are derived from the rules and limitations of AISC341-16 which include [22]:

1. Axial force constrains of X-shaped members of the special zone. The axial strength required the diagonal members of the web in the special zone under dead and also the living loads should not exceed the value of the following equation:

$F_{\text {Xaxial }}=0.03 F_{y} A_{g} / \alpha s$,

where:

$F_{y}$ : specified minimum yield stress

$A_{g}$ : gross area of the X-shaped members of the special zone

$\alpha_{s}$ : LRFD-ASD force level adjustment factor (1.0 for LRFD and 1.5 for ASD)

The axial force constraint of the X-shaped members of the special zone is defined as follows:

Constraint $1=\sum_{i=1}^{n} \max \left(\left(f_{\text {Xaxial }} / F_{\text {Xaxial }}-1\right), 0\right)$.

2. Constrains of axial force of special zone beam. As the axial strength of the upper and lower flange members in the special zone, which is determined according to the limit state of the tensile yield, and must be equal to or greater than 2.2 times of the demand strength:

$F_{\text {Baxial }}=\varphi F_{n}=0.9 F_{y} A_{g}$,

where:

$F_{y}$ : specified minimum yield stress

$A_{g}$ : gross area of the special zone beam

The axial force constrains of the special zone beam is defined as follows:

Constraint $2=\sum_{i=1}^{n} \max \left(\left(2.2 f_{\text {Baxial }} / F_{\text {Baxial }}-1\right), 0\right)$.
3. Shear force constrains in the middle of the beam of the special zone. Members of the upper and lower flange members in the special area must provide at least $25 \%$ of the required shear strength. The expected shear strength in the special zone, $V_{n e}$, in the middle of the span is determined as follows:

$L V_{n e}=\frac{3.6 R_{y} M_{n c}}{L_{s}}+0.036 E I \frac{L}{L_{s}^{3}}+R_{y}\left(P_{n t}+0.3 P_{n c}\right) \sin \alpha,(11)$

where:

$E$ : Modulus of elasticity of steel

I: Moment of inertia of a chord member of the special segment

$L$ : span length of the truss

$L_{s}$ : Length of the special segment

$M_{n c}$ : Nominal flexural strength of a chord member of the special segment

$P_{n c}$ : Nominal axial compressive strength of a diagonal member of the special segment

$P_{n t}$ : Nominal axial tensile strength of a diagonal member of the special segment

$\alpha$ : angle of diagonal members with the horizontal

The first two terms of the equation are based on a special part of Vierendeel without diagonal webs and the third term is needed only when there is an X-shaped diagonal member. The shear force constrains in the middle of the special zone beam is defined as follows:

Constraint $3=\sum_{i=1}^{n} \max \left(\left(V / 0.25 V_{n e}-1\right), 0\right)$.

4. Constrains of the combination of axial and flexural force are shown in columns. The combined effect of flexural and axial force in members with a cross-section with one or two axes of symmetry with a limit of $0.1 \leq I_{y c} / I_{y} \leq 0.9$ in which $I_{y}$ is the moment of inertia of the whole section and $I_{y c}$ is the moment of inertia of the compressive flange around the weak y axis. It is determined as follows:

$$
\begin{aligned}
& \text { For } \frac{P_{u}}{\varphi P_{n}} \geq 0.2 \\
& \operatorname{Comb}_{(\text {axial_Moment })}=\frac{P_{u}}{\varphi P_{n}}+\frac{8}{9}\left(\frac{M_{u x}}{M_{c x}}+\frac{M_{u y}}{M_{c y}}\right), \\
& \text { For } \frac{P_{u}}{\varphi P_{n}}<0.2 \\
& \operatorname{Comb}_{(\text {axial-Moment })}=\frac{P_{u}}{\varphi P_{n}}+\left(\frac{M_{u x}}{M_{c x}}+\frac{M_{u y}}{M_{c y}}\right),
\end{aligned}
$$

where: 
$P_{u}:$ Demand strength of design

$\varphi P_{n}$ : Axial strength of design

$M_{u x}$ : Demand flexural strength of the strong $\mathrm{x}$ axis

$M_{u y}$ : Demand flexural strength of the strong y axis

$M_{c x}$ : Design flexural strength of the strong x-axis

$M_{c y}$ : Design flexural strength of the strong y-axis

The Constrains of the combination of axial and flexural force in the columns are defined as follows:

Constraint $4=\sum_{i=1}^{n} \max \left(\left(\operatorname{Comb}_{(\text {axial-Moment })}-1\right), 0\right)$.

5. Stability index constraints. The stability index $\theta_{i}$ in structures should not be greater than $\theta_{\max }$. In these cases, there is a possibility of instability of the structure and its design should be reconsidered.

$\theta_{i}=\left[\frac{P_{u} \Delta_{e u}}{V_{u} h}\right]_{i}$

$P_{u i}$ : The sum of dead and living loads in stories $i$ to $n$, the last floor, in limit state
$\Delta_{\text {eui }}$ : The initial relative lateral displacement in the story i resulting from linear analysis

$V_{u i}$ : The total shear force applied to story $i$

$h_{i}$ : Story height $i$

$\theta_{\text {max }}=\frac{0.65}{C_{d}} \leq 0.25$

The limit of the stability index is defined as follows:

Constraint5 $=\sum_{i=1}^{n} \max \left(\left(\theta_{i} / 0.25^{-1}\right), 0\right)$.

Finally, $C_{g}$ is defined as follows:

$C_{g}=$ Constraint $1+$ Constraint $2+$ Constraint 3

+ Constraint $4+$ Constraint5.

In the present research study, the optimization code is written in Matlab [33] software and OpenSEES [34] software is used for structural analysis. The following Fig. 5 flowchart shows the process of optimizing the truss flexural frame using the island genetic algorithm.

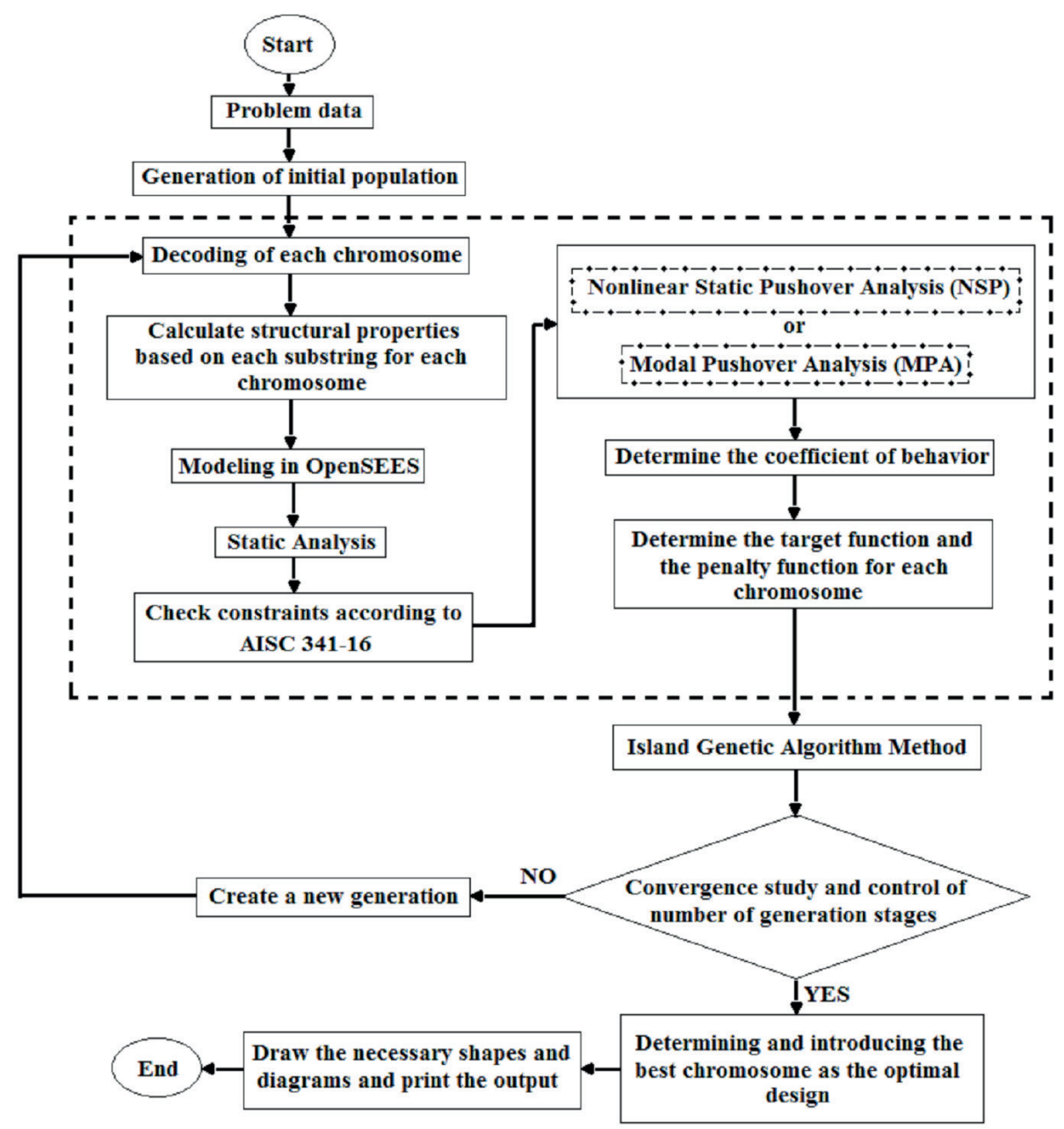

Fig. 5 Flowchart of the Process of Optimizing 


\section{Numerical examples}

In this section, five frames of 3, 6, 9, 12 and 15 stories are optimized with a story height of 3 meters and span length of 18 meters (Fig. 6). Initially, it has been assumed in the designs that the frames are placed in regular plans. The soil of the construction site is of type 2 and the project area is in a relatively high-risk zoning.

The applied dead load is $0.5 \mathrm{ton} / \mathrm{m}^{2}$ for all floors. Yet, the live load was set $0.2 \mathrm{ton} / \mathrm{m}^{2}$ for the floors and $0.12 \mathrm{ton} / \mathrm{m}^{2}$ on the roof. Lateral load enters the structure as a triangular load $Q=1.1(D+L)$. In this study, the dimensions of the column change every 3 floors. Although this increases the weight of the material to some extent, it reduces the cost of construction (such as column patches). The sections used in the optimization process are shown in Fig. 7 in which 8 types of sections are considered. Type 1 columns with BOX section, Type 2 with double section UNP boosted with sheet and other types with double section UNP.

Nonlinear static analysis in OpenSEES software was used to extract the effective parameters in determining the response modification factor. OpenSEES is an open

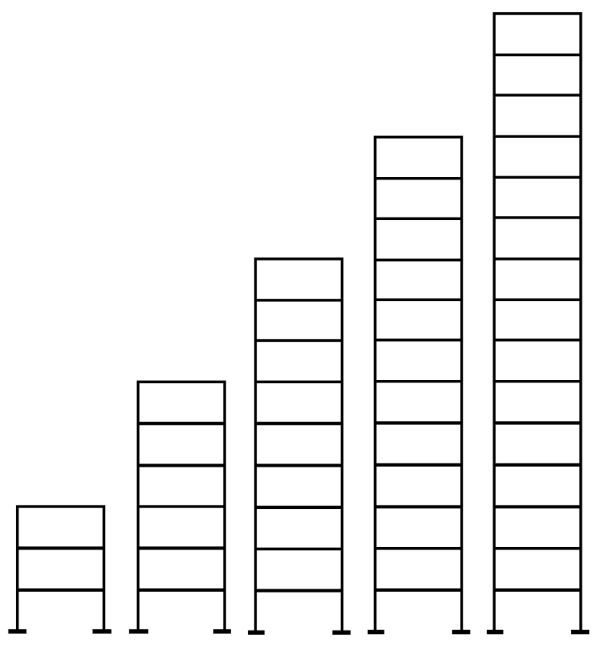

Fig. 6 View of the studied models

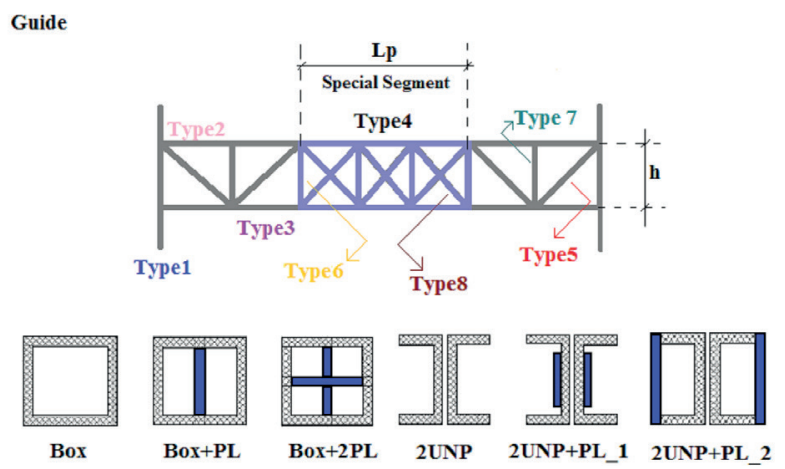

Fig. 7 Cross-sections source and finite element program that can to model nonlinear systems with different materials and elements. In the present study, geometric nonlinear effects are considered as P-Delta effect and nonlinear effects of materials are considered through fiber sections. In addition to the type of modeling method, the accuracy of modeling also depends on the behavioral models of the materials. The material behavior curve for all members is defined using the Uniaxial Material Steel 01 command, which is used for steel with two-line behavior and kinematic stiffness. As can be seen in Fig. 8, this behavior is quite symmetrical in the tensile and compressive branches.

Fig. 9 shows a model of the cyclic behavior of steel 01 without isotropic hardening, in which case the area of the hysteresis rings remains almost constant.

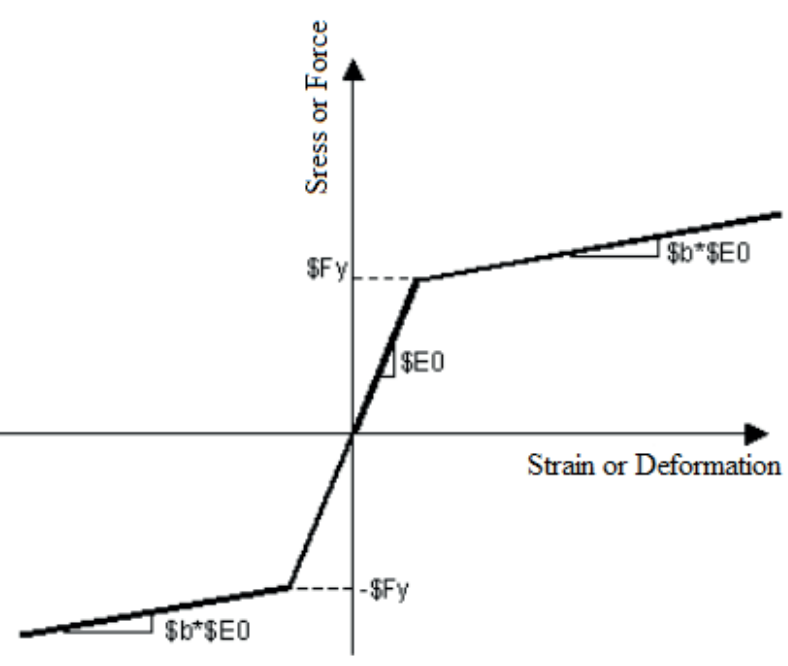

Fig. 8 Response curve for the steel01

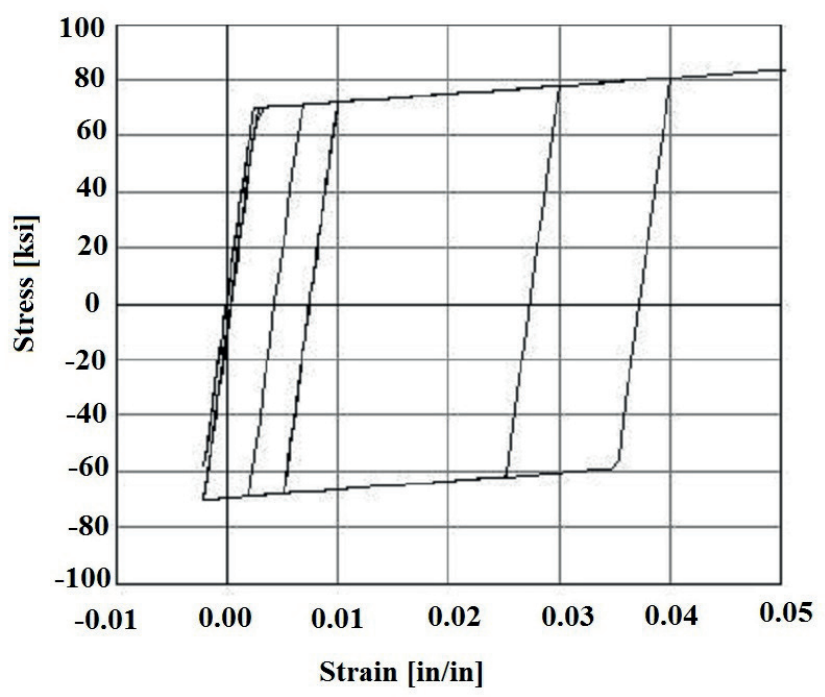

Fig. 9 The model of the cyclic response of Steel01 without isotropic hardening 


\subsection{Three-story frame}

In this section, the goal was to optimize the three-story frame with one bay. Figs. 10 and 11 show the changes in the value of the objective function to converge to the optimal 3-story structure during the optimization process with NSP analysis and MPA analysis, respectively. Table 1 shows the design results, including the arrangement of the truss and the final sections for each type. Figs. 12 and 13 show the optimal truss.

\subsection{Six-story frame}

In this example, the optimal design of the six-story frame with one bay was performed. Figs. 14 and 15 illustrate the convergence curve for the optimal 6-story structure during the optimization process with NSP analysis and MPA

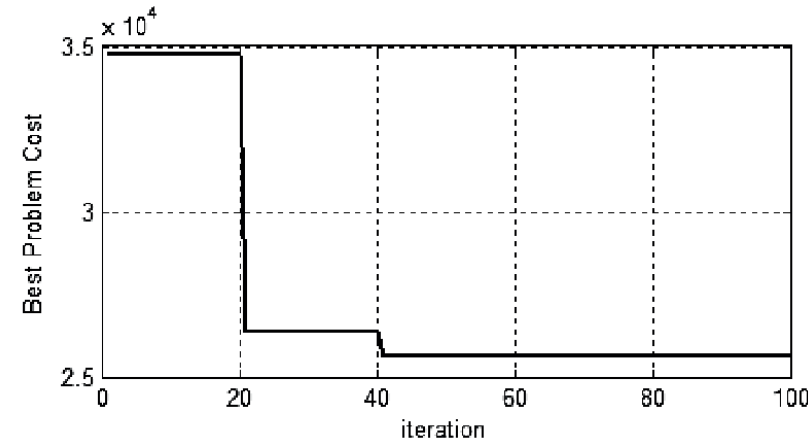

Fig. 10 The changes in the value of the objective function to converge to the optimal 3-story structure during the optimization process with NSP analysis

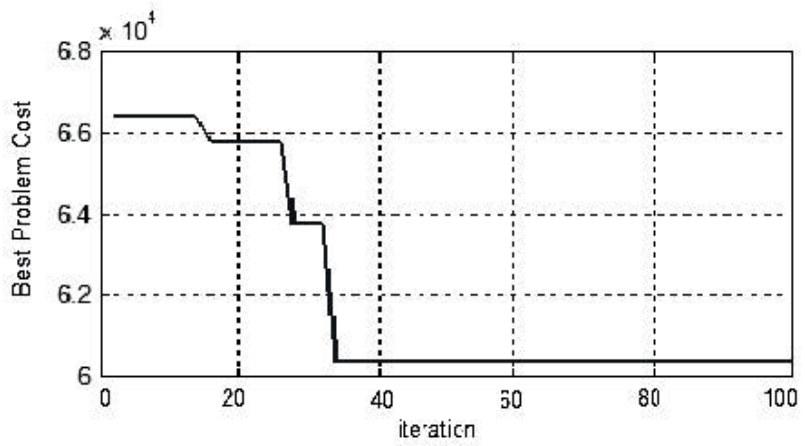

Fig. 11 The changes in the value of the objective function to converge to the optimal 3-story structure during the optimization process with MPA analysis analysis, respectively. Table 2 shows the design results of the models, including the arrangement of the truss and the final sections for each type. Figs. 16 and 17 show the optimal truss arrangement under NSP and MPA analyzes.

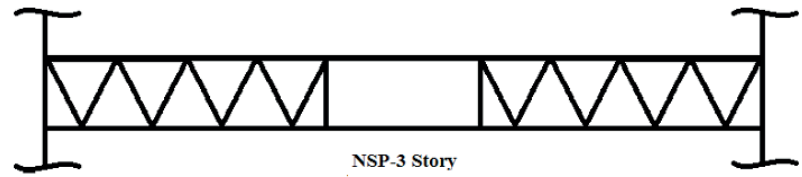

Fig. 12 The optimal truss arrangement under NSP analysis

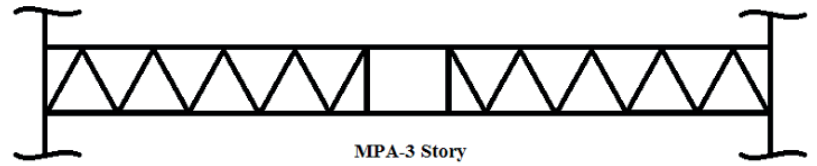

Fig. 13 The optimal truss arrangement under MPA analysis

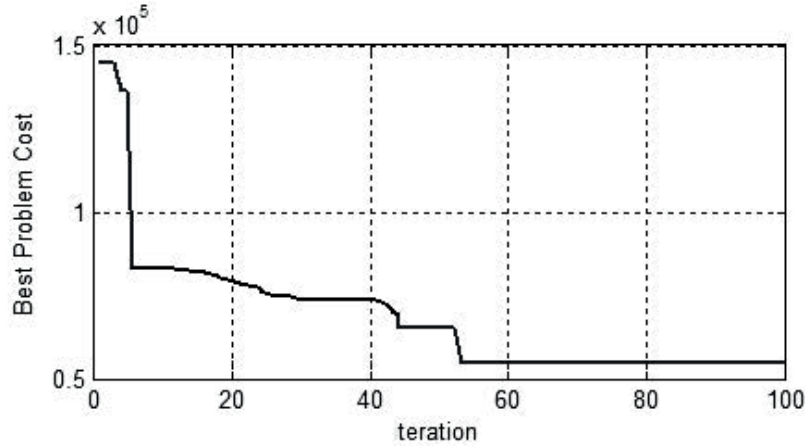

Fig. 14 The changes in the value of the objective function to converge to the optimal 6-story structure during the optimization process with NSP analysis

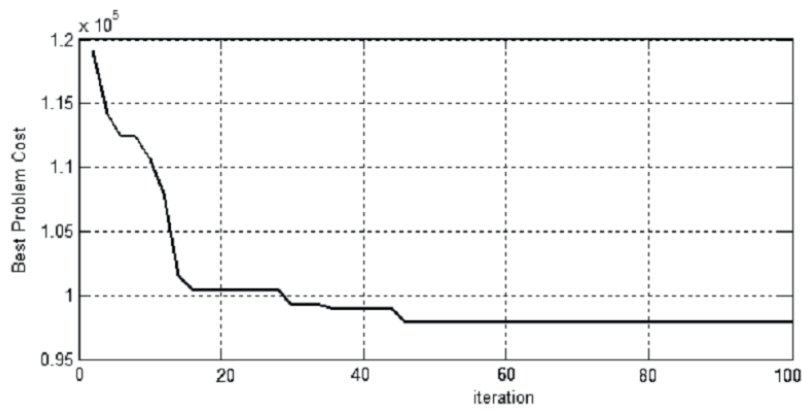

Fig. 15 The changes in the value of the objective function to converge to the optimal 6-story structure during the optimization process with MPA analysis

Table 1 The design results of the 3-story frame

\begin{tabular}{|c|c|c|c|c|c|c|c|c|c|c|c|}
\hline Story & Type 1 & Type 2 & Type 3 & Type 4 & Type 5 & Type 6 & Type 7 & Type 8 & $\mathrm{~h}$ & Lp & $\mathrm{R}$ \\
\hline \multicolumn{12}{|l|}{ NSP } \\
\hline $1-3$ & BOX $180 * 20+$ PL20 & 2UNP80+PL10_2 & 2UNP80 & 2UNP80 & 2UNP80 & 2UNP80 & - & - & 1 & 3.15 & 7.89 \\
\hline \multicolumn{12}{|l|}{ MPA } \\
\hline $1-3$ & $\mathrm{BOX} 500 * 30$ & 2UNP120+PL12_2 & 2UNP120 & 2UNP120 & 2UNP100 & 2UNP100 & - & - & 0.85 & 1.8 & 7.95 \\
\hline
\end{tabular}


Table 2 The design results of the 6-story frame

\begin{tabular}{|c|c|c|c|c|c|c|c|c|c|c|c|}
\hline Story & Type 1 & Type 2 & Type 3 & Type 4 & Type 5 & Type 6 & Type 7 & Type 8 & $\mathrm{~h}$ & Lp & $\mathrm{R}$ \\
\hline \multicolumn{12}{|l|}{ NSP } \\
\hline $1-3$ & BOX $180 * 20+$ PL 20 & 2UNP80 + PL15_2 & 2UNP80 & 2UNP80 & 2UNP80 & 2UNP80 & - & - & 1.4 & 2.7 & 7.81 \\
\hline $4-6$ & $\mathrm{BOX} 180 * 20$ & 2UNP80 + PL15_2 & 2UNP80 & 2UNP80 & 2UNP80 & 2UNP80 & - & - & & & \\
\hline \multicolumn{12}{|l|}{ MPA } \\
\hline $1-3$ & BOX $280 * 20$ & 2UNP120 + PL4_2 & 2UNP120 & 2UNP120 & 2UNP100 & 2UNP100 & - & - & 0.8 & 4.95 & 7.96 \\
\hline $4-6$ & BOX $280 * 20$ & 2UNP120 + PL4_2 & 2UNP120 & 2UNP120 & 2UNP100 & 2UNP100 & 2UNP80 & - & & & \\
\hline
\end{tabular}

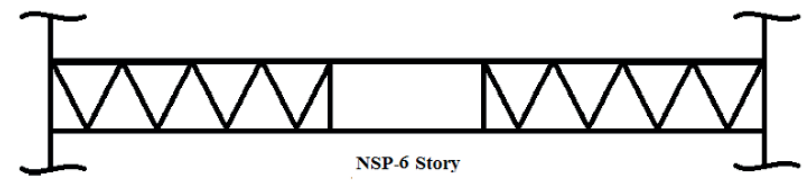

Fig. 16 The optimal truss arrangement under NSP analysis

\subsection{Nine-story frame}

This example deals with optimization of the nine-story frame with one bay. Figs. 18-19 the convergence curves for this example are illustrated for the optimization process with NSP analysis and MPA analysis, respectively. Table 3 shows the optimum design results of the models, including the arrangement of the truss and the final sections for each type. Figs. 20 and 21 show the optimal truss arrangement under NSP and MPA analyzes.

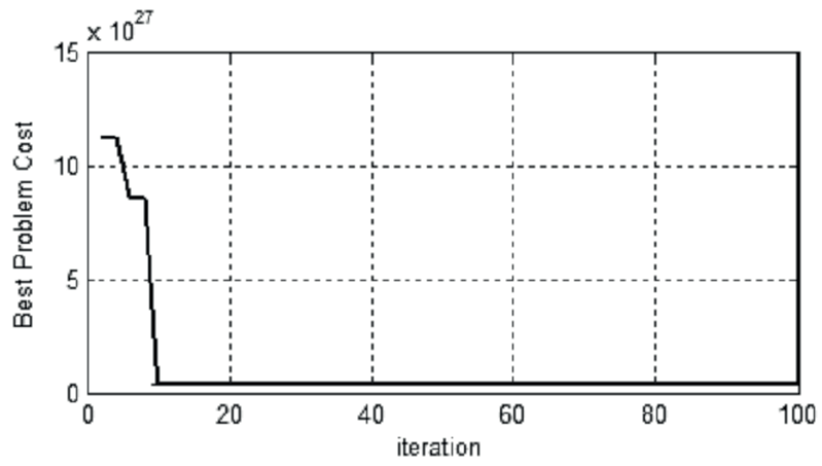

Fig. 18 The changes in the value of the objective function to converge to the optimal 9-story structure during the optimization process with NSP analysis

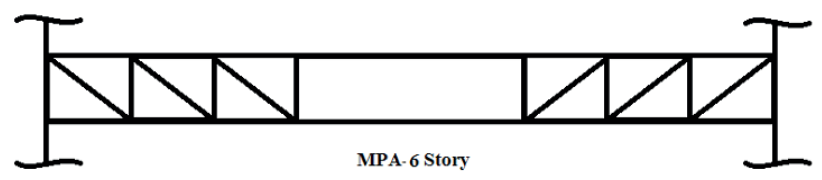

Fig. 17 The optimal truss arrangement under MPA analysis

\subsection{Twelve-story frame}

In this example, to check the results of high-rise frames, the optimal design of the Twelve-story frame with one bay was performed. Figs. 22-23 the convergence curves for this example are illustrated for the optimization process with NSP analysis and MPA analysis, respectively. Table 4 shows the optimum design results of the models, including the arrangement of the truss and the final sections for each type. Figs. 24 and 25 show the optimal truss arrangement under NSP and MPA analyzes.

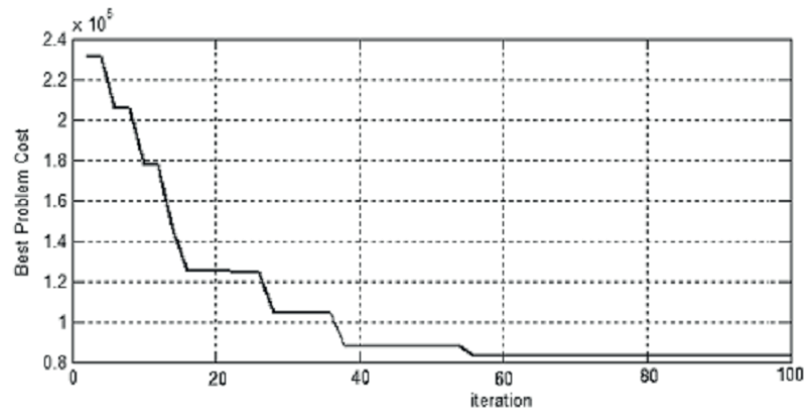

Fig. 19 The changes in the value of the objective function to converge to the optimal 9-story structure during the optimization process with MPA analysis

Table 3 The design results of the 9-story frame

\begin{tabular}{|c|c|c|c|c|c|c|c|c|c|c|c|}
\hline Story & Type 1 & Type 2 & Type 3 & Type 4 & Type 5 & Type 6 & Type 7 & Type 8 & $\mathrm{~h}$ & Lp & $\mathrm{R}$ \\
\hline \multicolumn{12}{|l|}{ NSP } \\
\hline $1-3$ & BOX $180 * 20$ & 2UNP100 + PL4_2 & 2UNP100 & 2UNP100 & 2UNP80 & 2UNP80 & - & - & 1.8 & 5.4 & 5.15 \\
\hline $4-6$ & $\mathrm{BOX} 180 * 20$ & 2UNP100 + PL4_2 & 2UNP100 & 2UNP100 & 2UNP80 & 2UNP80 & - & - & & & \\
\hline $7-9$ & $\mathrm{BOX} 180 * 20$ & 2UNP100 + PL4_2 & 2UNP100 & 2UNP100 & 2UNP80 & 2UNP80 & - & - & & & \\
\hline \multicolumn{12}{|l|}{ MPA } \\
\hline $1-3$ & $\mathrm{BOX} 200 * 20$ & $2 \mathrm{UNP} 100+\mathrm{PL}^{2} \_2$ & 2UNP100 & 2UNP100 & 2UNP80 & 2UNP80 & - & - & 1.1 & 8.1 & 7.79 \\
\hline $4-6$ & BOX $200 * 20$ & 2UNP100 + PL6_2 & 2UNP100 & 2UNP100 & 2UNP80 & 2UNP80 & - & - & & & \\
\hline $7-9$ & BOX $180 * 20+2$ PL 20 & 2UNP100 + PL5_2 & 2UNP100 & 2UNP100 & 2UNP80 & 2UNP80 & - & - & & & \\
\hline
\end{tabular}




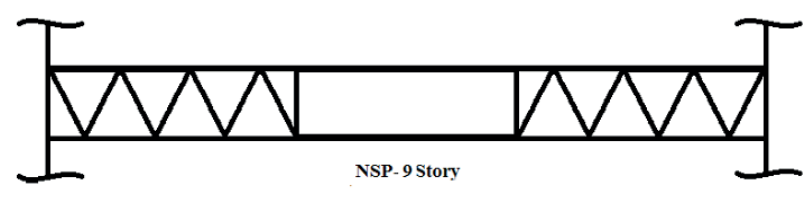

Fig. 20 The optimal truss arrangement under NSP analysis

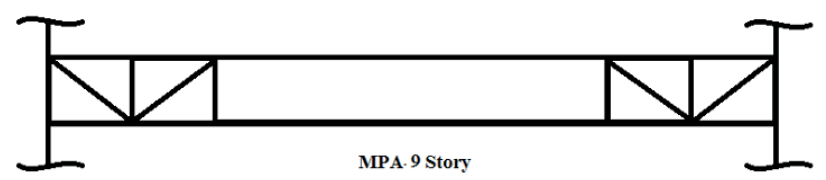

Fig. 21 The optimal truss arrangement under MPA analysis

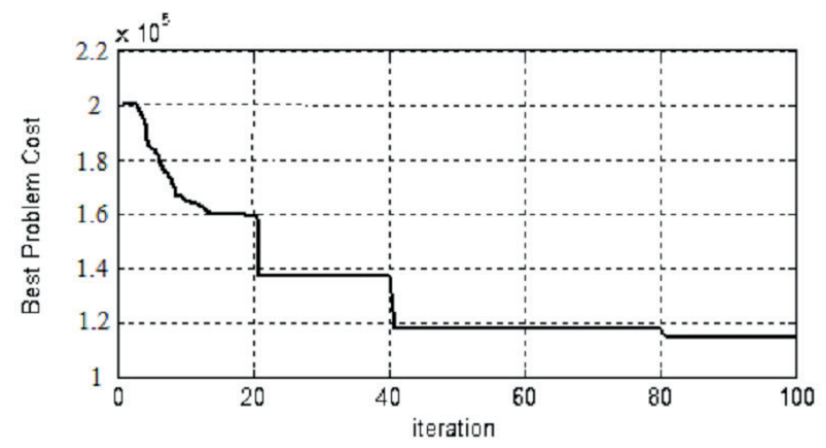

Fig. 22 The changes in the value of the objective function to converge to the optimal 12-story structure during the optimization process with NSP analysis

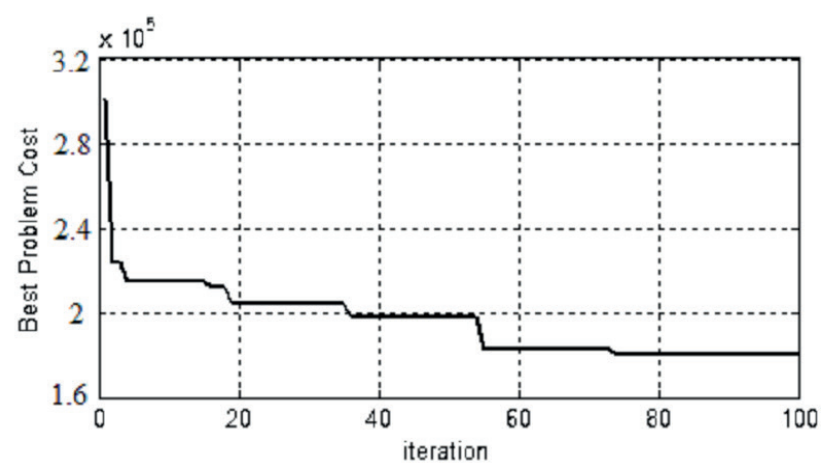

Fig. 23 The changes in the value of the objective function to converge to the optimal 12-story structure during the optimization process with

MPA analysis

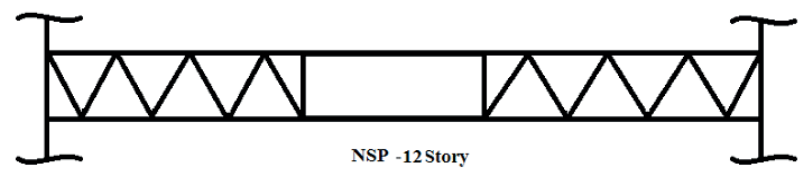

Fig. 24 The optimal truss arrangement under NSP analysis

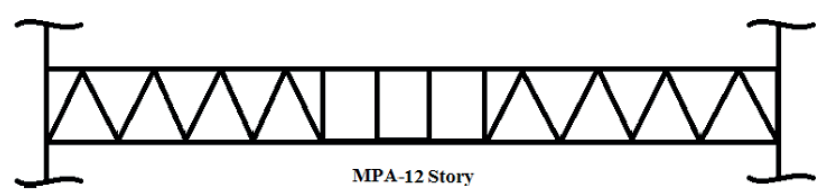

Fig. 25 The optimal truss arrangement under MPA analysis

\subsection{Fifteen-story frame}

This example deals with optimization of the Fifteen-story frame with one bay. Figs. 26 and 27 show the changes in the value of the objective function to converge to the optimal 15-story structure during the optimization process with NSP analysis and MPA analysis, respectively. Table 5 shows the design results, including the arrangement of the truss and the final sections for each type. Figs. 28 and 29 show the optimal truss arrangement under NSP and MPA analyzes.

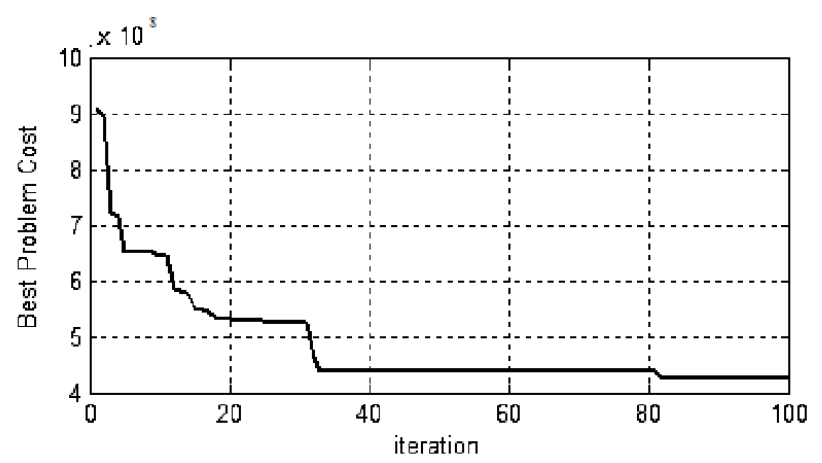

Fig. 26 The changes in the value of the objective function to converge to the optimal 15 -story structure during the optimization process with NSP analysis

Table 4 The design results of the 12-story frame

\begin{tabular}{|c|c|c|c|c|c|c|c|c|c|c|c|}
\hline Story & Type 1 & Type 2 & Type 3 & Type 4 & Type 5 & Type 6 & Type 7 & Type 8 & $\mathrm{~h}$ & $\mathrm{Lp}$ & $\mathrm{R}$ \\
\hline \multicolumn{12}{|l|}{ NSP } \\
\hline $1-3$ & BOX $240 * 20$ & 2UNP100 + PL15_2 & 2UNP100 & 2UNP100 & 2UNP80 & 2UNP80 & - & - & 1.8 & 4.6 & 6.41 \\
\hline $4-6$ & $\mathrm{BOX} 240 * 20$ & 2UNP100 + PL15_2 & 2UNP100 & 2UNP100 & 2UNP80 & 2UNP80 & - & - & & & \\
\hline $7-9$ & $\mathrm{BOX} 240 * 20$ & 2UNP100 + PL12_2 & 2UNP100 & 2UNP100 & 2UNP80 & 2UNP80 & - & - & & & \\
\hline $10-12$ & $\mathrm{BOX} 240 * 20$ & 2UNP100 + PL12_2 & 2UNP100 & 2UNP100 & 2UNP80 & 2UNP80 & - & - & & & \\
\hline \multicolumn{12}{|l|}{ MPA } \\
\hline $1-3$ & BOX $240 * 30+2$ PL 20 & 2UNP80 + PL15_1 & 2UNP80 & 2UNP80 & 2UNP80 & 2UNP80 & - & - & 1.7 & 3.6 & 6.64 \\
\hline $4-6$ & $\mathrm{BOX} 240 * 30+\mathrm{PL} 20$ & 2UNP80 + PL12_1 & 2UNP80 & 2UNP80 & 2UNP80 & 2UNP80 & - & - & & & \\
\hline $7-9$ & $\mathrm{BOX} 240 * 30$ & 2UNP80 + PL12_1 & 2UNP80 & 2UNP80 & 2UNP80 & 2UNP80 & - & - & & & \\
\hline $10-12$ & BOX $240 * 30$ & 2UNP80 + PL12_1 & 2UNP80 & 2UNP80 & 2UNP80 & 2UNP80 & - & - & & & \\
\hline
\end{tabular}




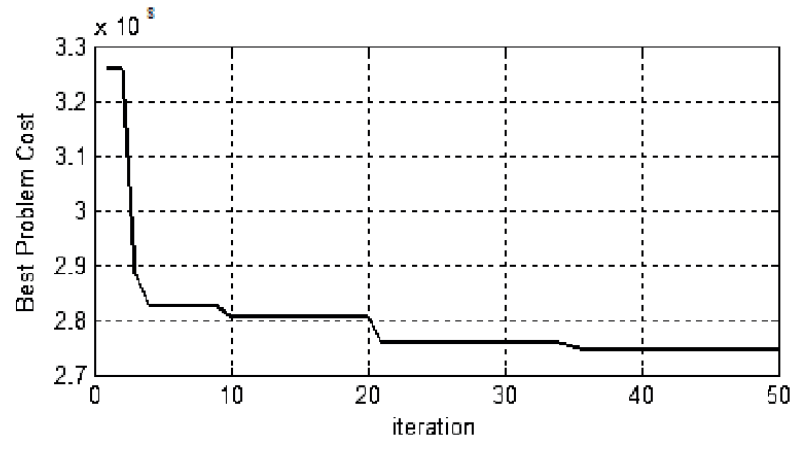

Fig. 27 The changes in the value of the objective function to converge to the optimal 15-story structure during the optimization process with

MPA analysis

Fig. 30 shows the weight of the structures resulting from the optimization process. As can be seen, the use of MPA method increases the weight of the optimized structure. The weight of 3,6 , and 9 story structures has increased by 137 , 82 , and 5 percent, respectively, and also 12 and 15 story structures have increased by 17 and 5 percent. It is observed that that this weight difference between NSP and MPA methods decreased with increasing the height of the structure.

\section{The selected earthquake records}

Due to the large dispersions of the dynamic response from one record to another, it is necessary to use a group of strong ground motions with the same physical structure. Selected records of this research include a set of strong records that have been recorded in areas near and far from the fault. The most important physical parameters of selected records such as peak ground acceleration (PGA), peak ground velocity (PGV) and magnitude with momentum criteria $(\mathrm{Mw})$ are shown in Table 6 , respectively. The MRP record is a far-field and other records are in the near-field classification [35].

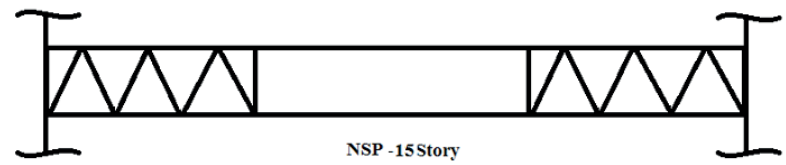

Fig. 28 The optimal truss arrangement under NSP analysis

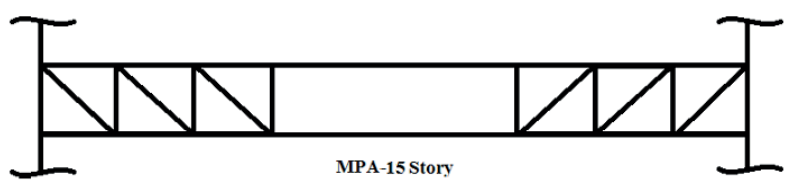

Fig. 29 The optimal truss arrangement under MPA analysis

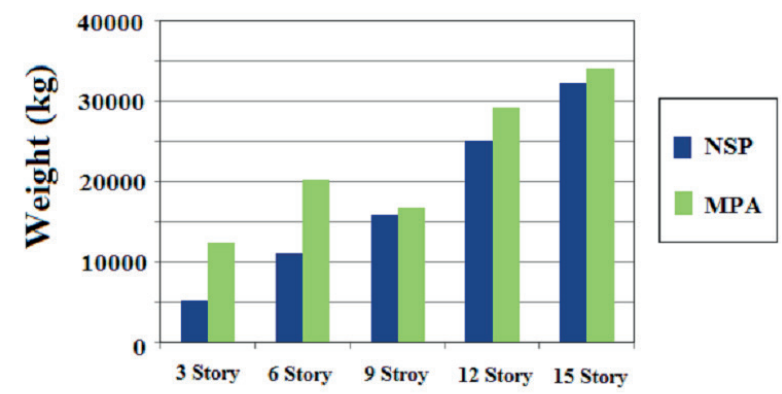

Fig. 30 The weight of the structures resulting from the optimization process

\section{Discussion on nonlinear results}

In order to evaluate the seismic performance of the optimized structures, nonlinear dynamic analysis of time history using a set of 7 near-domain records and 1 far-domain record on these models was performed by Open SEES software.

One of the important criterion in designing process is evaluating and studying the trend of relative displacement changes (drift) on stories of structure. Thus, if the allowable limit of this parameter does not met within the allowable range of the regulations, the level of seismic performance corresponding to the nonlinear response range of the

Table 5 The design results of the 15-story frame

\begin{tabular}{|c|c|c|c|c|c|c|c|c|c|c|c|}
\hline Story & Type 1 & Type 2 & Type 3 & Type 4 & Type 5 & Type 6 & Type 7 & Type 8 & $\mathrm{~h}$ & Lp & $\mathrm{R}$ \\
\hline \multicolumn{12}{|l|}{ NSP } \\
\hline $1-3$ & BOX $240 * 20+$ PL 20 & 2UNP100 + PL12_2 & 2UNP100 & 2UNP100 & 2UNP100 & 2UNP100 & - & - & 1.6 & 5.25 & 5.04 \\
\hline $4-6$ & BOX $240 * 20+$ PL 20 & 2UNP100 + PL12_2 & 2UNP100 & 2UNP100 & 2UNP100 & 2UNP100 & - & - & & & \\
\hline $7-9$ & BOX $240 * 20$ & 2UNP100 + PL12_2 & 2UNP100 & 2UNP100 & 2UNP100 & 2UNP100 & - & - & & & \\
\hline $10-12$ & BOX $240 * 20$ & 2UNP100 + PL12_2 & 2UNP100 & 2UNP100 & 2UNP100 & 2UNP100 & - & - & & & \\
\hline $13-15$ & BOX $240 * 20$ & $2 \mathrm{UNP} 100+$ PL12_2 & 2UNP100 & 2UNP100 & 2UNP100 & 2UNP100 & - & - & & & \\
\hline \multicolumn{12}{|l|}{ MPA } \\
\hline $1-3$ & BOX $260 * 20$ & 2UNP100 + PL4_2 & 2UNP100 & 2UNP100 & 2UNP100 & 2UNP100 & 2UNP100 & - & 0.85 & 6.75 & 5.47 \\
\hline $4-6$ & BOX $240 * 30+2$ PL 20 & 2UNP80 + PL20_2 & 2UNP80 & 2UNP80 & 2UNP80 & 2UNP80 & 2UNP80 & - & & & \\
\hline $7-9$ & BOX $240 * 30+$ PL 20 & 2UNP80 + PL20_2 & 2UNP80 & 2UNP80 & 2UNP80 & 2UNP80 & 2UNP80 & - & & & \\
\hline $10-12$ & BOX $240 * 30$ & 2UNP80 + PL15_2 & 2UNP80 & 2UNP80 & 2UNP80 & 2UNP80 & 2UNP80 & - & & & \\
\hline $13-15$ & BOX $240 * 20+2$ PL 20 & 2UNP80 + PL12_2 & 2UNP80 & 2UNP80 & 2UNP80 & 2UNP80 & 2UNP80 & - & & & \\
\hline
\end{tabular}


Table 6 The selected earthquake records (PEER Ground Motion Database [35] )

\begin{tabular}{|c|c|c|c|c|}
\hline Ground Motion & $\begin{array}{l}\text { Magnitude } \\
(\mathrm{Mw})\end{array}$ & $\begin{array}{l}\text { PGA } \\
(\mathrm{g})\end{array}$ & $\begin{array}{l}\mathrm{PGV} \\
(\mathrm{cm} / \mathrm{s})\end{array}$ & $\begin{array}{l}\text { PGD } \\
(\mathrm{cm})\end{array}$ \\
\hline $\begin{array}{l}\text { Imperial Valley } 1979 \\
\text { Array E06-1.0Km }\end{array}$ & 6.5 & 0.439 & 110.93 & 70.07 \\
\hline $\begin{array}{l}\text { Loma Prieta } 1989 \\
\text { Los Gatos (LGP)-6.1Km }\end{array}$ & 6.9 & 0.963 & 95.87 & 54.14 \\
\hline $\begin{array}{l}\text { Cape Mendocino } 1992 \\
\text { Petrolia (PET)-9.5Km }\end{array}$ & 7.1 & 0.662 & 89.54 & 29.40 \\
\hline $\begin{array}{l}\text { Landers } 1992 \\
\text { Lucern Valley (LCN)- } \\
8.9 \mathrm{Km}\end{array}$ & 7.2 & 0.901 & 124.61 & 110.29 \\
\hline $\begin{array}{l}\text { Northridge } 1994 \\
\text { Sylmar (SYL)-6.4Km }\end{array}$ & 6.7 & 0.843 & 129.35 & 32.21 \\
\hline $\begin{array}{l}\text { Northridge } 1994 \\
\text { Sepuelveda (SEP)-8.9Km }\end{array}$ & 6.7 & 0.753 & 84.8 & 18.48 \\
\hline $\begin{array}{l}\text { Tabas } 1978 \\
\text { Tabas City-3.0Km }\end{array}$ & 7.4 & 0.851 & 121.3 & 94.5 \\
\hline $\begin{array}{l}\text { Northridge } 1994 \\
\text { Moorpark Fire sta. (MRP)- } \\
8.9 \mathrm{Km}\end{array}$ & 6.7 & 0.29 & 20.7 & 4.24 \\
\hline
\end{tabular}

main elements of the structure can exceed the safety limit. The maximum relative displacement cap of the floors corresponding to each of the earthquake records for the structures optimized by NSP and MPA methods is obtained and their average for all earthquakes at the height of the structure in Figs. 31-32, respectively. The error obtained from these methods is also shown in the following figures.

As can be seen from the figure, the relative displacement profiles predicted by both methods in the middle classes deviate from the nonlinear time history analysis response profile. In all structures, the MPA method has less error as well as a better performance than the NSP method in estimating the relative displacement response of the structural classes. The difference in error between the two methods becomes more noticeable as the number of structural floors increases. It is also observed that the optimized 9, 12, 15 story structures under the NSP analysis of the average maximum drift response, does not satisfy the code limit for buildings with a greater main period time of $0.7 \mathrm{sec}$ equal to 0.02 . The reason for this poor performance of the NSP method can be attributed to the main approximations of this method, which is because of the constant considering the lateral force distribution and determining the final response of the structure based on the first mode.

The structures of these frames have a base period of about 1 second and more because of having large openings of 18 meters. Also, the period of higher modes of these structures compared to the period of corresponding vibrational modes in ordinary frames, has a greater potential to create resonance under the effect of earthquakes with a pulse period of 1 second and more. Evaluation of the seismic response structure of the structures reveals that the highest relative displacement of the floors occurred under three strong records near PET, SPV and SYL. Fig. 33 shows how the cumulative kinetic energy changes corresponding to the records used in the study. It is observed that the energy release process of all three records occurs in a relatively short period of 2 seconds. The physical manifestation of this process will be the dynamic behavior of the earth in several powerful shocks and at very short intervals as well. The nature of the large pulses of displacement of the earth in these records will bring about a sharp increase in the seismic response in the skeletons of structures with the period of the first mode or the second mode around this time step.

Analytical study of the relative displacement response diagrams of the floors reported a significant reduction of this parameter in the optimized models under MPA analysis, especially in the 9, 12, 15 story models. Therefore, MPA method can be regarded as a suitable alternative to NSP method for tall buildings where the participation of these modes is determinant due to its ability to influence high modes in the structural response.

\section{Conclusions}

In the present study, the optimization formulation of special truss moment frame using island genetic algorithm under NSP and MPA analyzes was presented. To show the efficiency of the method presented in the present study, five frames of 3, 6, 9, 12 and 15 stories were examined thereafter. Finally, as can be seen in the convergence diagrams of the optimization process, the initial design differs significantly from the final design (optimal design) regarding the amount of weight and coefficient of behavior of the structure. Therefore, due to the use of this structure in large openings, the application of the optimization process could have significant impact on the volume of steel consumed as well as the proposed methods have shown the ability to optimally design these frames. Evaluation of seismic performance of designed structures was performed by implementing a set of time-history dynamic analysis. The results of this study showed that the use of MPA method causes a large reduction in the drift rate of stories. Comparison of diagrams related to maximum response showed that MPA method has better accuracy in estimating maximum structural response than NSP method. The difference in 

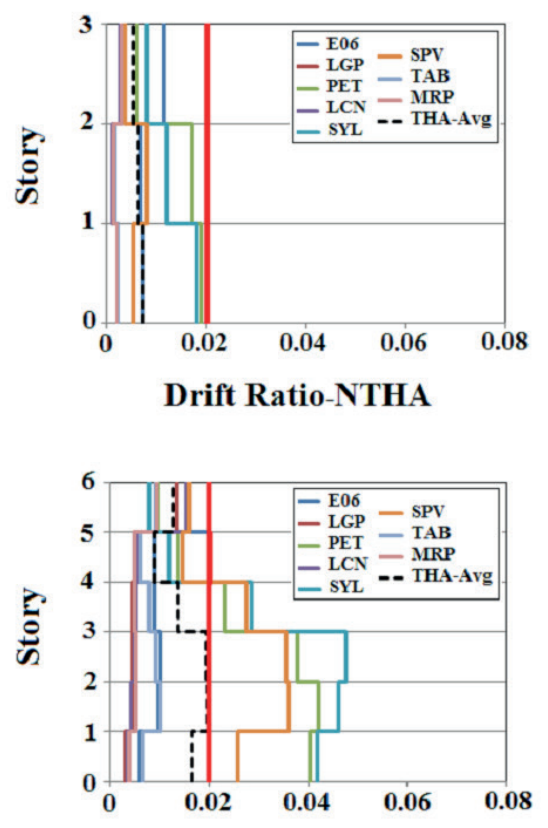

Drift Ratio-NTHA
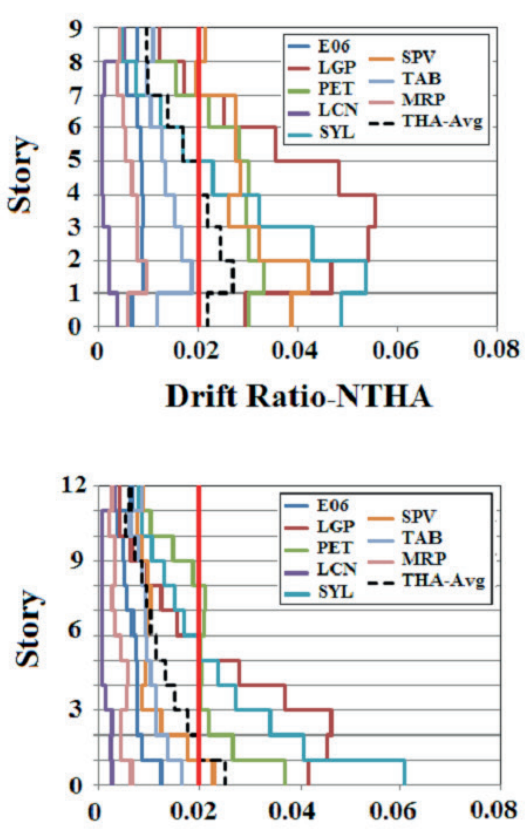

Drift Ratio-NTHA

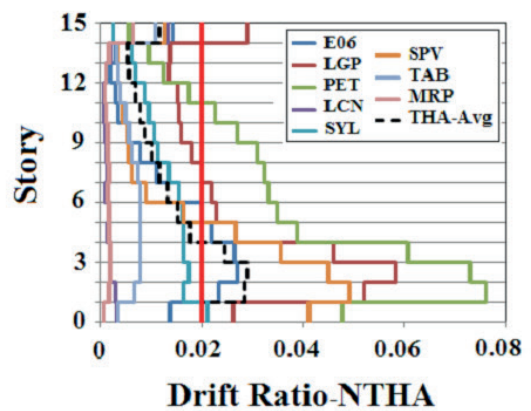

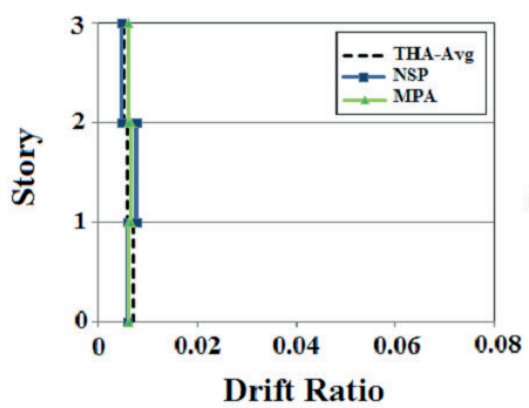
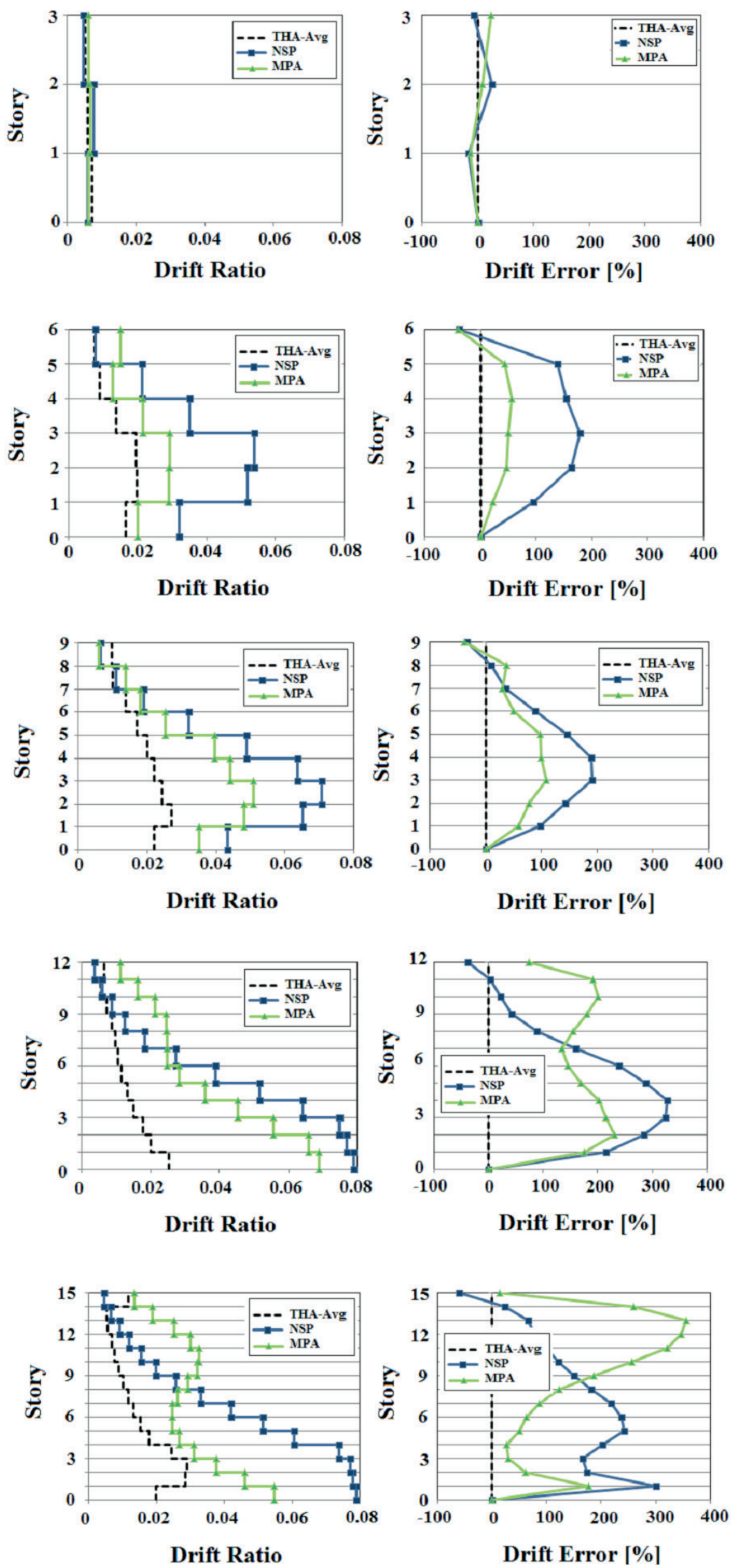

Fig. 31 Maximum response of structures designed with NSP method and prediction error in each analysis method" 


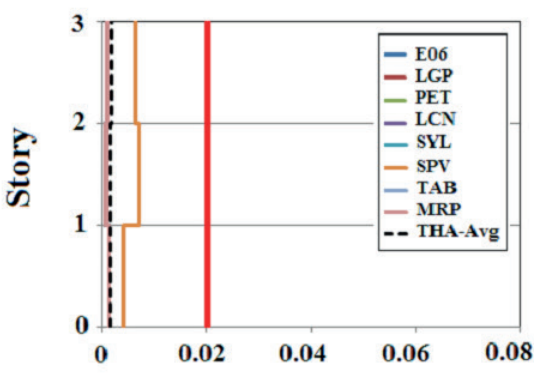

Drift Ratio-NTHA

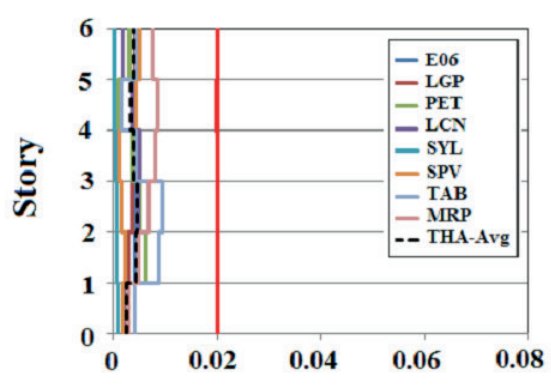

Drift Ratio-NTHA

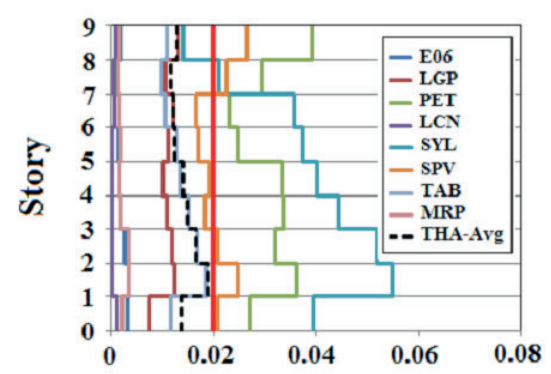

Drift Ratio-NTHA

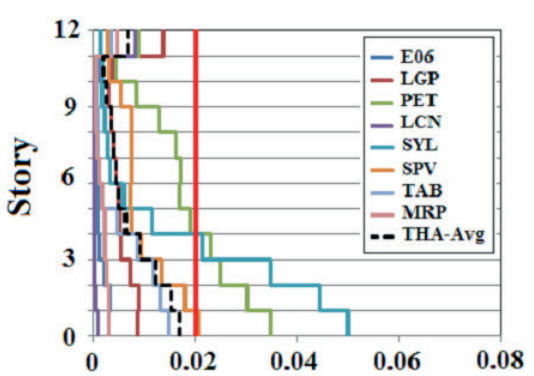

Drift Ratio-NTHA

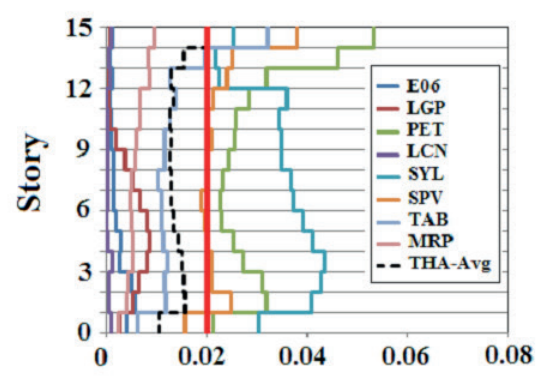

Drift Ratio-NTHA
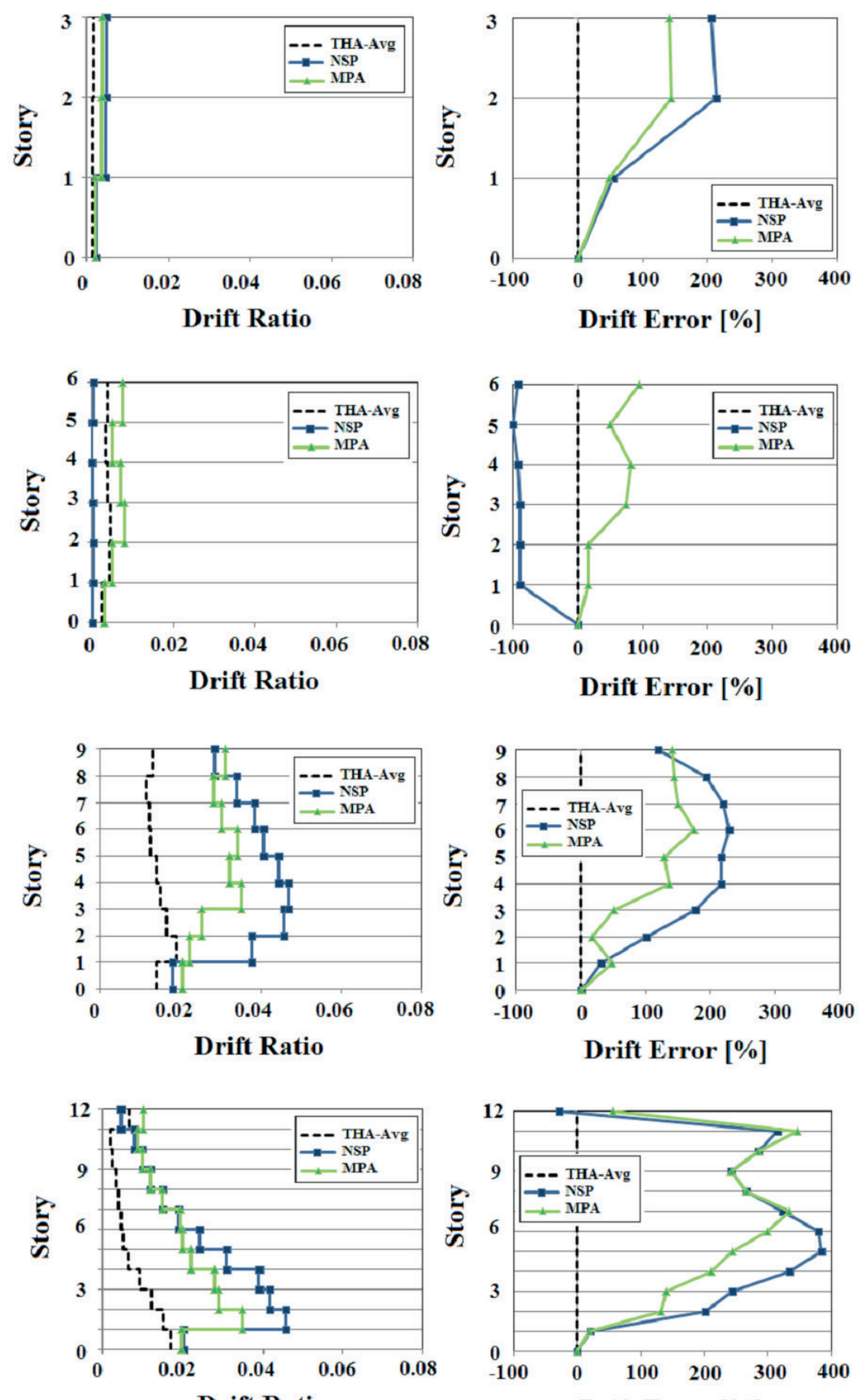

Drift Ratio
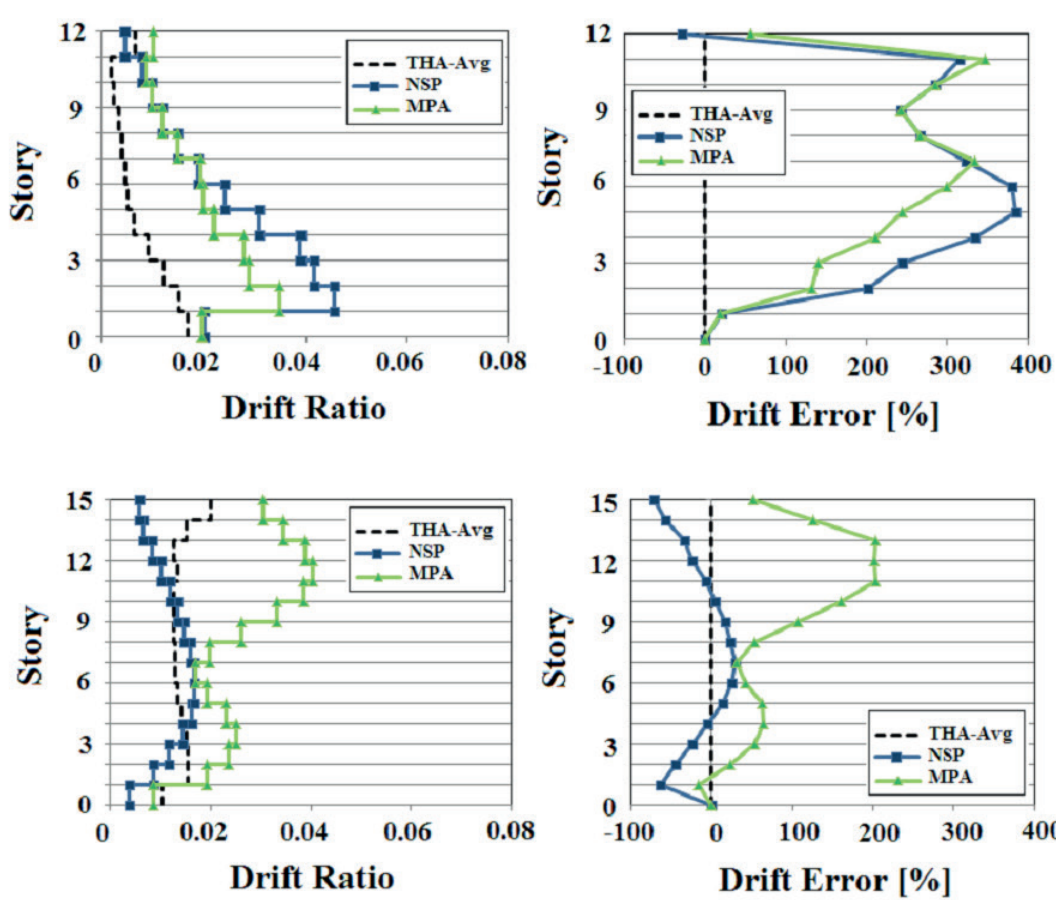

Fig. 32 Maximum response of structures designed with MPA method and prediction error in each analysis method 


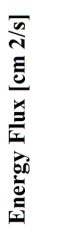

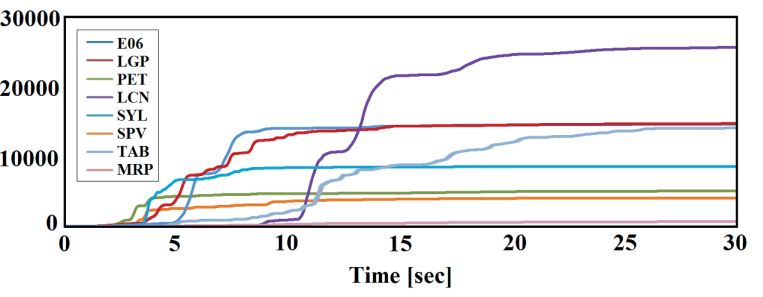

Fig. 33 The cumulative kinetic energy changes corresponding to the records used in the study

maximum response estimation in NSP and MPA methods was more noticeable in the middle floors of the structure. Also, based on the findings of this research, it was explained as the use of MPA analysis method causes an

\section{References}

[1] Yahmi, D., Branci, T., Bouchaïr, A., Fournely, E. "Evaluating the Behaviour Factor of Medium Ductile SMRF Structures", Periodica Polytechnica Civil Engineering, 62(2), pp. 373-385, 2018.

https://oi.org/10.3311/PPci.10419

[2] Reyes-Salazar, A., Bojórquez, E., Bojórquez, J., Valenzuela-Beltran, F., Gaxiola-Camacho, J. R., Haldar, A. "Seismic reduction factor evaluation and its components for steel buildings undergoing nonlinear deformations", Current Science, 116(11), pp.1850-1860, 2019. https://doi.org/10.18520/cs/v116/111/1850-1860

[3] Massumi, A., Tasnimi, A. A., Saatcioglu, M. "Prediction of seismic overstrength in concrete moment resisting frames using incremental static and dynamic analyses", presented at 13th World Conference on Earthquake Engineering, Vancouver, BC, Canada, Aug. 1-6, 2004. [online] Available at: https://www.researchgate. net/publication/232703213

[4] Mahmoudi, M., Zaree, M. "Evaluating response modification factors of concentrically braced steel frames", Journal of Constructional Steel Research, 66(10), pp.1196-1204, 2010.

https://doi.org/10.1016/j.jcsr.2010.04.004

[5] Chopra, A. K., Goel, R. K. "A modal pushover analysis procedure for estimating seismic demands for buildings", Earthquake Engineering and Structural Dynamics, 31(3), 561-582, 2002.

https://doi.org/10.1002/eqe.144

[6] Goel, R. K., Chopra, A. K. "Evaluation of Modal and FEMA Pushover Analyses: SAC Buildings", Earthquake Spectra, 20(1), pp. 225-254, 2004.

https://doi.org/10.1193/1.1646390

[7] Kalkan, E., \& Chopra, A. K. "Modal-Pushover-Based GroundMotion Scaling Procedure", Journal of Structural Engineering, 137(3), pp. 298-310, 2011.

https://doi.org/10.1061/(ASCE)ST.1943-541X.0000308

[8] Hassan, W. M., Reyes, J. C. "Assessment of modal pushover analysis for mid-rise concrete buildings with and without viscous dampers", Journal of Building Engineering, 29, Article number: 101103, 2020. https://doi.org/10.1016/j.jobe.2019.101103 increase in the weight of the structure. Furthermore, this increase in weight in short-rise structures is about $100 \%$ increase in the weight of the structure, which leads to a non-economic design. As a medium to high-rise structures, it can be said that this method can be a good alternative to NSP method due to its ability to affect high modes in the response of the structure, which eventually causes its optimal performance.

\section{Acknowledgement}

The authors wish express their sincere thanks to the anonymous reviewers for their constructive comments that have helped improving the quality of this paper.

[9] Guan, M., Liu, W., Du, H., Cui, J., Wang, J. "Combination model for conventional pushover analysis considering higher mode vibration effects", The Structural Design of Tall and Special Buildings, 28(12), Article ID: e1625, 2019. https://doi.org/10.1002/tal.1625

[10] Qiu, D., Chen, J., Xu, Q. "Improved pushover analysis for underground large-scale frame structures based on structural dynamic responses", Tunnelling and Underground Space Technology, 103, Article number: 103405, 2020. https://doi.org/10.1016/j.tust.2020.103405

[11] Goel, S. C., Itani, A. M. "Seismic-Resistant Special Truss-Moment Frames", Journal of Structural Engineering, 120(6), pp. 1781-1797, 1994.

https://doi.org/10.1061/(ASCE)0733-9445(1994)120:6(1781)

[12] Goel, S. C., Itani, A. M. "Seismic Behavior of Open-Web TrussMoment Frames", Journal of Structural Engineering, 120(6), pp. 1763-1780, 1994. https://doi.org/10.1061/(ASCE)0733-9445(1994)120:6(1763)

[13] Basha, H., Goel, S. C. "Seismic resistant truss moment frames with ductile vierendeel segment", [pdf] In: Eleventh Word Conference on Earthquake Engineering, Ann Arbor, MI, USA, 1994, Paper No. 487. Available at: http://www.iitk.ac.in/nicee/wcee/article/11_487.PDF

[14] Goel, S. C., Rai, D. C., Basha, H. S. "Special truss moment frames: Design Guide", University of Michigan, Ann Arbor, MI, USA, Report No. UMCEE 98-44, 1998.

[15] Parra-Montesinos, G. J., Goel, S. C., Kim, K. Y. "Behavior of Steel Double-Channel Built-Up Chords of Special Truss Moment Frames under Reversed Cyclic Bending", Journal of Structural Engineering, 132(9), pp. 1343-1351, 2006. https://doi.org/10.1061/(ASCE)0733-9445(2006)132:9(1343)

[16] Chao, S.-H., Goel, S. C. "A Modifi ed Equation for Expected Maximum Shear Strength of the Special Segment for Design of Special Truss Moment Frames", Engineering Journal, 45(2), pp. 117-125, 2008. [online] Available at: https://www.researchgate.net/ publication/289588405 
[17] Chao, S.-H., Goel, S. C. "Performance-Based Plastic Design of Special Truss Moment Frames", Engineering journal, 45(2), pp. 127-150, 2008. [online] Available at: https://www.researchgate.net/ publication $/ 255600732$

[18] Pekcan, G., Linke, C., Itani, A. "Damage avoidance design of special truss moment frames with energy dissipating devices", Journal of Constructional Steel Research, 65(6), pp. 1374-1384, 2009. https://doi.org/10.1016/j.jcsr.2008.08.012

[19] Abdollahzadeh, G., Sazjini, M., Asghari, A. "Seismic Fragility Assessment of Special Truss Moment Frames (STMF) Using the Capacity Spectrum Method", Civil Engineering Infrastructures Journal, 48(1), pp. 1-8, 2015. https://doi.org/10.7508/ceij.2015.01.001

[20] Mousavi, S., Keramat, A., Shekasteband, B. "Investigation of the Effect of Geometric Parameters on Behavior of Special Truss Moment Frames", International Research Journal of Engineering and Technology (IRJET), 6(7), pp. 1566-1573, 2019. [online] Available at: https://www.researchgate.net/publication/335013921

[21] Kumar, R., Sahoo, D. R. "Seismic performance of high-rise special truss moment frames with multiple Vierendeel ductile segments and high panel aspect ratios", The Structural Design of Tall and Special Buildings, 29(18), Article ID: e1810, 2020.

https://doi.org/10.1002/tal.1810

[22] AISC "Seismic Provisions for Structural Steel Buildings", [pdf] American Institute of Steel Construction, Chicago, IL, USA, Rep. ANSI/AISC 341-16, 2016. Available at: https://www.aisc.org/globalassets/aisc/publications/standards/seismic-provisions-for-structural-steel-buildings-ansi-aisc-341-16.pdf

[23] Kaveh, A., Khosravian, M. "Size/Layout Optimization of Truss Structures Using Vibrating Particles System Meta-heuristic Algorithm and its Improved Version", Periodica Polytechnica Civil Engineering, 2021.

https://doi.org/10.3311/PPci.18670

[24] Serpik, I. N., Alekseytsev, A. V., Balabin, P. Y. "Mixed approaches to handle limitations and execute mutation in the genetic algorithm for truss size, shape and topology optimization", Periodica Polytechnica Civil Engineering, 61(3), pp. 471-482, 2017. https://doi.org/10.3311/PPci.8125

[25] Kaveh, A., Kalatjari, V. "Size/geometry optimization of trusses by the force method and genetic algorithm", ZAMM Journal of Applied Mathematics and Mechanics, 84(5), pp. 347-357, 2004. https://doi.org/10.1002/zamm.200310106

[26] Kaveh, A., Zaerreza, A. "Size/Layout Optimization of Truss Structures Using Shuffled Shepherd Optimization Method", Periodica Polytechnica Civil Engineering, 64(2), pp. 408-421, 2020. https://doi.org/10.3311/PPci.15726
[27] Chao, S.-H., Jiansinlapadamrong, C., Simasathien, S., Okazaki, T. "Full-scale testing and design of special truss moment frames for high-seismic areas", Journal of Structural Engineering, 146(3), Article number: 04019229, 2020. https://doi.org/10.1061/(ASCE)ST.1943-541X.0002541

[28] Sadeghpour, M., Kalatjari, V. R., Pahlavan, H. "Numerical study of the effect of geometric arrangement of the truss on the response modification factor of the special truss moment frame (STMF)", SN Applied Sciences, 3, Article number: 584, 2021.

https://doi.org/10.1007/s42452-021-04570-z

[29] Sophianopoulos, D. S., Ntina, M. I. "Investigation of the seismic performance of a single story - Single bay special truss moment frame with SMAs incorporated", Structures, 33, pp. 2374-2387, 2021.

https://doi.org/10.1016/j.istruc.2021.05.093

[30] Kalatjari, V. R. Talebpour, M. H. "Optimization of skeletal structures using improved genetic algorithm based on proposed sampling search space idea", International Journal of Optimization in Civil Engineering, 8 (3), pp. 415-432, 2018. [online] Available at: http:// ijoce.iust.ac.ir/article-1-353-fa.html

[31] Kaveh, A., Kalatjari, V. R., Talebpour, M. H., Torkamanzadeh, J. "Configuration optimization of trusses using a multi heuristic based search method", Iran University of Science \& Technology, 3(1), pp. 151-178, 2013. [online] Available at: http://ijoce.iust.ac.ir/article-1124-en.html

[32] Maroofi, E., KalatJari, V. R. "Seismic Performance Improvement of Truss Moment Frames Using Genetic Algorithm", presented at 6th National Conference on Applied Research in Civil Engineering, Architecture and Urban Management and the 5th Specialized Exhibition of Housing and Building Mass Builders in Tehran Province, Tehran, Iran, Aug, 13-14, 2019. [online] Available at: https://civilica.com/doc/928009/ [in Persian]

[33] The Math Works Inc "MATLAB, (version 2013a)" [computer program] Available at: https://www.mathworks.com/products/matlab. html [Accessed: 12 August 2019]

[34] OpenSees "Open System for Earthquake Engineering Simulation, (version 2.4.5)", [computer program] Available at: http:// opensees. berkeley.edu/ [Accessed: 12 August 2019]

[35] UC Berkley "Ground Motion Database", [online] Available at: https://peer.berkeley.edu/peer-strong-ground-motion-databases [Accessed: 26 September 2019] 